\title{
DÖRTYOL AĞZINDAN DERLENEN BİR HALK ANLATISINDA PEKISTTTIRME AMACIYLA KULLANILAN BAZI UNSURLAR ${ }^{1}$
}

Araştırma Makalesi / Research Article

\begin{abstract}
Haşimi, A. (2020). Dörtyol Ağzından Derlenen Bir Halk Anlatısında Pekiştirme Amacıyla Kullanılan Bazı Unsurlar. Nevşehir Hacı Bektaş Veli Üniversitesi SBE Dergisi, 10(2), 832-845.
\end{abstract}

DOI: $10.30783 /$ nevsosbilen.790521
Geliş Tarihi: 30.08 .2020

Kabul Tarihi: 31.12 .2020

E-ISSN: $2149-3871$

Ahmet HAŞİMi

Hatay Mustafa Kemal Üniversitesi, Fen Edebiyat Fakültesi, Türk Dili ve Edebiyatı Bölümü ahmethasimi@mku.edu.tr

ORCID No: 0000-0002-9244-8157

DÖRTYOL AĞZINDAN DERLENEN BİR HALK ANLATISINDA PEKISSTTIRME AMACIYLA KULLANILAN BAZI UNSURLAR

ÖZ

Yüzyıllar boyunca Anadolu insanı dış etkilere aldırmayarak duygu ve düşüncelerini sade ama güçlü bir Türkçeyle ifade edebilmiştir. Dilde üsluba yükseklik kazandıran çeşitli unsurlar vardır. Bu unsurlardan birisi de pekiştirmelerdir. Türkçede pekiştirmeler; ses, biçim birimi, sözcük, söz dizimi ve daha başka unsurlarla yapılır. Dörtyol ilçesi Türk dilini ve kültürünü koruması açısından Anadolu'da önemli yerlerden birisidir. Bu çalışmada araştırmaya dayanak oluşturan metin Hatay’ın Dörtyol ilçesinden derlenmiştir. Derleme metninin konusu Hazreti Âdem'in cennetten çıkarılması ve dünyaya gönderilmesiyle, Hazreti Âdem'in Hazreti Havva ile dünyada tekrar kavuşması hadisesidir. Elde edilen metin, cümle bağlamından da hareketle, kelimelere eklenen unsurlar, kelimeler, söz dizimi unsurları pekiştirme özelliği taşıyıp taşımadıkları açısından dikkatle incelenmeye çalışılmıştır. Derleme metni üzerinde yapılan inceleme sonucunda metinde ses, biçim birimi ve söz dizimi unsurlarının pekiştirme görevinde kullanıldığı tespit edilmiştir. Çalışmada, bu tespitler sınıflandırmaya tabi tutularak her bir unsur ait olduğu sınıfa dâhil edilmiştir. Bunlardan bazıları standart Türkçede de bulunmayan ve dile zenginlik katan pekiştirme unsurlarıdır.

Anahtar Kelimeler: Halk Anlatısı, Pekiştirme, Anadolu Ağıları, Dörtyol Ağzı.

\section{SOME ELEMENTS USED FOR REINFORCEMENT IN A FOLK NARRATIVE COMPILED FROM DIALECT OF DÖRTYOL INGILIZCE MAKALE BAŞLIĞI}

\begin{abstract}
ABSTACT
For centuries, Anatolia has been able to express its feelings and thoughts in plain but powerful Turkish, ignoring human beings to external influences. There are various elements in language that add height to style. One of these elements is reinforcement. Reinforcements in Turkish; It is made by means of phoneme, suffix, word, syntax and more. Dörtyol district is one of the important places in Anatolia in terms of preserving the Turkish language and culture. In this study, the text that forms the basis of the research was compiled from the district of Dörtyol in Hatay. The subject of the compilation text is the event that Saint Adam reunites with Hazrat Eve in the world by removing Adam from heaven and sending it to the world. The text obtained has been carefully examined in terms of whether the elements which added to the words, words and syntax elements have reinforcement properties, starting from the context of the sentence. As a result of the review made on the compilation text, phoneme, morpheme and syntax elements were used to reinforce the text. In the study, these determinations were subjected to classification and each element was included in the class to which it belongs. Some of these are reinforcement elements that do not exist in standard Turkish and add richness to the language.

Key Words: Folk Narrative, Reinforcement, Anatolian Dialect, Dialect of Dörtyol.

\footnotetext{
${ }^{1}$ Bu makale, 24-26 Ekim 2019 tarihleri arasında Iğdır'da III. Uluslararası Bilimler Işığında Yaratılış Kongresi’nde sunulan "Hatay Dörtyol Ağzında İnsanoğlunun Yaratılması ve Hazreti Âdem'in Dünyaya Gönderilmesi Anlatısı Üzerine Bazı Değerlendirmeler" adlı bildirinin gözden geçirilmiş biçimidir.
} 


\section{GİRIŞ}

\subsection{Dörtyol'un Tarihi}

İlk defa 1071 Malazgirt zaferinden sonra Müslüman Türklerle tanışan Dörtyol ve çevresine çoğunluğu Oğuzların Üçok koluna mensup Türkmenler yerleşmiştir. Dörtyol'un ilk yerleşim yeri Özerli'dir ve ilk yöneticileri de Özeroğulları'dır. Dolayısıyla Dörtyol'un kuruluş yılları 11. yüzyılın sonlarına dayanmaktadır. Âşık Paşazade'ye göre Özeroğulları'nın Çukurova'ya gelmesi Süleyman Şah Gazi'nin Caber Kalesi önünde boğulmasının ardından konar-göçerlerin etrafa dağılmasıyla gerçekleşmiştir. Dörtyol adına ilk defa 1870'lerden itibaren tapu kayıtlarında Payas kazasının bir mevkii olarak rastlamaktayız. Kaza merkezi Aralık 1906 yılında Payas'tan Erzin'e taşınmıștır. Dörtyol mevkii merkez olmak üzere Şubat 1909 'da, Dörtyol adıyla Adana vilayeti, Cebel-i Bereket Sancağı'na bağlı kaza merkezi oldu. Nisan 1910'dan itibaren Dörtyol kazasının adı Ümraniye olarak değiştirilmiştir. 2 Nisan 1912 tarihinde ise Suriye vilayetindeki Ümraniye, Leski adlı Hamidiye kazasının Dörtyol ile posta vs.de karıştırılmaması için Akdam mevkii merkez olmak üzere Ümraniye'nin adı tekrar Dörtyol olarak değiştirilmiştir. Mondros ateşkes antlaşmasından sonra 11 Aralık 1918'de işgal edilen Dörtyol'da Milli Mücadele'nin ilk kurşunu 19 Aralık 1918'de Karakise köyünde Özerlili Hoca Ömer oğlu Mehmet (KARA) tarafından atılmıştır. Bu olaydan birkaç gün sonra Kara Hasan Paşa tarafından da Milli Mücadele'nin ilk Kuva-yı Milliye örgütü Dörtyol'da kurulmuştur. Fransız ve Ermenilerle yapılan mücadele sonucunda 9 Ocak 1922'de Dörtyol düşman işgalinden kurtarılmıştır (Yazıcı, 2006: 3-4).

Dörtyol, verimli toprakları ve yakınında İskenderun Demirçelik Fabrikası'nın bulunması dolayısıyla başka illerden göç alan bir ilçedir. Bununla birlikte kendi kültür yapısını korumuştur. Dörtyol'da yaşayan Türkler, Türkçenin ağız özelliklerini de koruyup günümüze kadar getirmiştir. Fakat eğitim seviyesinin artması ve kitle iletişim araçlarının yaygın olarak kullanılması yeni yetişen kuşakların standart Türkçeyle konuşmaya başlamasını beraberinde getirmiştir.

\subsection{Dörtyol'un Ăğz Özellikleri}

Karahan'ın (1996: 171) sınıflandırmasına göre, Anadolu ağızları arasında Dörtyol ağzı, Batı grubu ağızlarından VII. Alt gruba girmektedir.

Dörtyol ağzı ile ilgili akademik olarak yapılmış iki çalışmaya rastlanmıştır. Bunlardan biri Yazıcı (2006) tarafından yüksek lisans tezi olarak çalışılan Dörtyol Ağzı, diğeri de Öztürk (2009) tarafından doktora tezi olarak çalışılan Hatay Ağzı'dır. Öztürk'ün çalışması Hatay'ın tamamı içerisinde Dörtyol ağzını da kapsamaktadır.

Yazıcı'nın çalışmasında Dörtyol ağzıyla ilgili tespit edilen bazı hususlar şu şekildedir:

1. Çokluk eki ünsüz benzeşmesine uğrayarak $+n A r$ şeklini almıştır.

2. İlgi hâli ekinde, iyelik ikinci teklik ve çokluk şahıs eklerinde, zamir kökenli ikinci teklik ve çokluk şahıslarda diş ünsüzü $n$ yerine genellikle damak ünsüzü $\eta$ tercih edilir.

3. Aitlik eki Türkiye Türkçesi'ndeki +ki'nin yanı sıra yöre ağzında nadiren de olsa $y$ ile de karşılanmaktadır.

4. Belirtme hâl eki Dörtyol ağzında genellikle $+I,+U$ şeklinde olmasına rağmen bazen $+a$ ve $+e$ ile de karşılanmaktadır.

5. Yöre ağzında, özellikle orta hecede, hece kaynaşmasına ve ses düşmesine sıklıkla karşılaşılır.

6. Öğrenilen geçmiş zaman eki $-m I S ̧,-m U S ̧ s$ eklerinin haricinde $-I k,-U k$ şekli de kullanılmaktadır.

7. Şimdiki zaman eki -yor şeklinin dişında -yür,-yör,-yur,-yır,-yó,-yo,-yu,-yü,-yı şekilleri de görülmektedir.

8. Zarf fiil eklerinden -IncA ekinin yanı sıra bu görevi yöre ağzında -IşIn ekleri de kullanılmaktadır. $\mathrm{Bu}$ ek sonuna $k$ ünsüzünü de alarak bazen $-\operatorname{IncAk}$ şeklinde de kullanılmaktadır.

9. -ken eki yöre ağzından derlenen metinlerde bazen sonuna $e$ ve $a$ seslerini alarak, -kena, ķana şeklinde kullanılmaktadır. 
Çalışmamızda kendisinden derleme yapılan kaynak kişi Mehmet Fil, aslında Hassalı olup yaklaşık 50 yıldır Dörtyol'da ikamet etmektedir. Kendisi İskenderun Demirçelik Fabrikası'nda işçi olarak çalıştıktan sonra emekli olmuştur.

\subsection{Araştırmanın Amacı}

Hatay, tarih boyunca farklı kültürlerin bir arada yaşadığı bir kültür mozaiği şehri olmuştur. $\mathrm{Bu}$ gün de bu özelliğini devam ettirmektedir. Dörtyol da 7. yüzyıldan itibaren çeşitli Türk unsurlarının yerleşmiş olduğu Hatay ilinin sınırları içerisinde bulunmaktadır. Bugüne kadar standart Türkçede pekiştirme amacıyla kullanılan unsurlar üzerine pek çok çalışma yapılmıştır. Buna karşın Türkiye Türkçesi ağızlarında pekiştirme unsurları üzerine yapılan çalışmaların nitelik ve nicelik açısından yeterli olmadığı söylenebilir. Bu çalışma, Türkiye Türkçesi ağızlarında pekiştirme amacıyla kullanılan unsurlarla ilgili yapılan çalışmalara bir nebze de olsa katkı sağlayabilmeyi amaçlamaktadır.

\subsection{Araştırmanın Yöntemi}

Aşağıda literatür olarak verilen kısım bilim adamlarının pekiştirme meselesine nitelik ve yöntem açısından nasıl baktıklarını tespit etmeye yöneliktir. Literatür taraması sonucunda araştırmacıların görüşleri arasından, derleme metnindeki tespitlere daha uygun düştüğü için, Karagöz (2018) ve İpek'in (2009) çalışmaları sentezlenerek üç bölüm meydana getirilmiştir. Çalışmada daha önce yapılan çalışmalara atıf yapılarak tespit edilen pekiştirme unsurlarına destek sağlanmıştır. Hatay Dörtyol ağzından derlenen halk anlatısı, 63 satırdan oluşan bir metindir. Temmuz 2019' da derlenen ses kaydı aynı yıl içerisinde yazıya geçirilmiştir. Derleme metni incelenerek pekiştirme amacıyla kullanılan örnekler ilgili başlık altında verilmiş daha sonra da pekiştirme unsurunun niteliği ve kullanıış şekli hakkında kısa bir açıklama yapılmıştır. Tespit edilen pekiştirme unsurları art zamanlı ve eş zamanlı çalışmalarla karşılaştırılarak incelenmeye çalışılmıştır. Derlenen metinde pekiştirme sözcükleri veya sözcük grupları eğik yazı ile yazılmış pekiştirme görevi gören unsurlar da altı çizilerek gösterilmiştir. Sonuç kısmında ise anlatı metninde pekiştirme amacıyla tespit edilen unsurlar hakkında kısa bir değerlendirme yapılmış ve bundan sonra hangi çalışmaların yapılabileceği tartışı1mıştır.

\subsection{Pekiştirme Nedir?}

Güncel Türkçe Sözlük’te pekiştirme, pekiştirmek işi anlamında; pekiştirmek kelimesi ise 1. Sertleşmek, katılaştırmak. 2. Sağlamlaştırmak, tahkim etmek. 3. Güçlendirmek (mecaz) anlamlarında kullanılmıştır (TS. 2020).

Gerek dil bilgisi alanında yapılan çalışmalarda gerekse dil bilgisi terimleri sözlüklerinde pekiştirme kavramına yer verilmiştir.

Hatiboğlu, "Türkçede çok defa sıfatın, bazen adın ilk hecesindeki ünlünün, baştaki ünsüzle birlikte -p-, -m-, -r-, -s- ünsüzlerinden biriyle veya ünlüyle başlayan bir adın ya da sıfatın yalnız -pünsüzüyle kapatılmasından meydana gelen hecenin, aynı sıfatın veya aynı adın başına eklenmesiyle kurulan kıpkırmızı, sapsağlam veya sapasağlam, yemyeşil, tertemiz, mosmor, tastamam...” gibi sözcükleri "pekiştirmeli sözcük" genel başlığı altında verir (Hatiboğlu, 1972: 78).

Hengirmen, Dilbilgisi ve Dilbilim Terimleri Sözlüğü'nde pekiştirmeyi “Sözcüklere çeşitli yollarla pekiştirmeli bir anlam kazandırma işlemi” ş̧eklinde tanımlar. Araştırmacı, pekiştirme ile ilgili pekiştirme belirteci, pekiş̧irmeli özne, pekiştirmeli sıfat, pekiş̧irmeli tezlik eylemi pekiştirmeli yüklem, pekiştirme ünlüsünü madde başı olarak verir (Hengirmen, 1999: 304).

Üstüner de, Türkçede Pekiştirme adlı kitabında pekiştirmeyi şöyle tanımlar: "Dilin söz dizimi kurallarından, kelime, ek veya ses unsurlarından birini kullanarak, ifade edilenler arasındaki bir sözün belirginleştirilmesine; kelime, kelime grubu ve cümle gibi bir dil birliğinin anlamının güçlendirilmesine, kesinleştirilmesine veya belirttiği kavramın aşırılı̆̆ının belirtilmesine; bir unsura dikkat çekilmesine veya bu unsurun ön plana çıkarılmasına pekiştirme adı verilir" (Üstüner, 2003: 6).

Korkmaz, Gramer Terimleri Sözlügü’nde pekiștirmeyi “Kök kelimenin belirttiği özelliği çeşitli yollarla yoğunlaştırma" olarak tanımlar ve "pekiştirilmiş kelime" maddesine de göndermede bulunarak; "pekiştirilmiş kelime" terimiyle de: "İlk heceleri m, p, r, s, seslerinden biri ile kapatılan 
pekiştirilmiş, anlamı yoğunluk bakımından kuvvetlendirilmiş" sıfat, zarf veya isimleri kasteder (Korkmaz, 2007: 174).

Dilbilim Sözlüğü’nün "pekiştirme” maddesi, "niteleyici belirteç ve eylemlerin çeşitli yollarla anlamlarının arttırılması işlemi" biçiminde tanımlanmış ve "yemyeşil, kıpkırmızı, masmavi, tertemiz” sözcükleri ile örneklendirilmiştir (İmer, Kocaman, Özsoy, 2011: 212).

Sıfat ya da zarf görevindeki sözcüklerin anlamlarının türlü yollarla belirginleştirilip kuvvetlendirilmesine ve bu yolla söz konusu sözcüklerin, önlerinde yer alarak tümlediği başka adların ya da eylemlerin niteliklerinin daha üst bir dereceyle ifade etmesine Türkçenin ilk yazılı metinlerinden beri sıklıkla rastlanmaktadır. Tarihi Türk yazı dillerine ilişkin metin yayınları incelendiğinde kimi örnekleri Türkiye Türkçesindeki biçimlerle koşutluk taşıyan pekiştirilmiş sözcük kullanımları örneklenmiştir. Değişik yollarla yapılan bu pekiştirmeler arasında, hece yinelenmesi ile anlam yoğunlukları arttırılmış sıfatlar ve zarflar dikkat çekicidir (Ergene, 2013: 65).

\subsection{Türkçede Pekiştirme Alanında Yapılan Bazı Çalışmalar}

Türkçede pekiştirme üzerine makale, yüksek lisans ve doktora tezi düzeyinde yapılan çalışmalar bu çalışmaya yol gösterici nitelikte olacaktır. Bahsedilen çalışmaların kısa tanıtımı ve konuya yaklaşımları, yayınlanma tarihine göre aşağıda verilmiştir.

Aslan (2002), Türkiye Türkçesinde Slfat ve Zarfların Pekiştirme ve Derecelendirme Yolları adlı yüksek lisans tezinde, sıfat ya da zarf işlevli kelimelere tür dereceleri sağlayan yapılar anlatılmış, yapılara ait işlevler üzerinde durulmuştur. Ekler bahsinde, ek işlevlerinin daha net anlaşılması ve tarihsel sürecinin takip edilebilmesi için yer yer ek etimolojilerinden de bahsedilmiş, konuya açıklık getirmek için örnekler edebi eserlerden seçilerek ve künyeleri ile birlikte verilmiştir.

Sezer'in (2006: 157) Türkiye Türkçesi Ağızlarında Zarflar ve Zarf Yapımı adlı yüksek lisans tezinde de yer yer zarflarda pekiştirme konusuna değinilmiştir.

Ercilasun'un (2008) La Enklitiği ve Türkçede Bir Pekiştirme Enklitiği adlı kapsamlı makalesinde pekiştirme enklitiklerinin kelime türü ayırt etmediği, işlev olarak tek kelimeyle sınırlı olmayıp kelime gruplarını ve cümleyi de kapsayabileceği, ek sırası gözetmediği, eklerden önce de sonra da gelebileceği, üst üste gelebileceği, +çA, +tI eşitlik ekleriyle ve 1, n, y, m pekiştiricileriyle sıkça bir araya gelebileceği, birbirlerinin yerine kullanılabileceği, dilin ses özelliklerine uymak zorunda olmadığı, gramerleşmede rol oynayarak ekleşip kalıplaşabileceği ve yeni kelimeler yapabileceği, "pekiştirme" yanında "rica, istek, yalvarma, acıma, hayret, hitap, soru, bağlama, benzerlik, zaman" gibi anlam çalarları (nüansları) kazanabileceği, vurgusuz oldukları, kullanılmadıkları zaman, anlamdaki küçük farklılık dışında, "ağırlayıcı"dan çoğunlukla, bir şey eksilmeyeceği konuları üzerinde tespitlerde bulunulmuştur.

Ayrıca Ercilasun'un aynı çalışmasında (2008: 43) tarihî ve yaşayan Türk lehçe ve ağızlarında A(y), AgU (>Av), An, Aay, çU (> -çI, -şI, -sI, -jI), DA, du (dū, dō, duo), gIl, gU, hA, I, i, kAn, kA:(y), kü, 1A, 1I/lU, mA, mAt, mU, ne (>-nA), ok (>Ok,-ak, -k), sA, si, -sin,-şe, şU, U, -(I)y pekiştirme enklitikleri tespit edilmiştir.

İpek ise Türkçede Pekiştirme Edatları isimli doktora çalışmasında, pekiştirmeleri:

1. Seslerle Yapılan Pekiştirme,

2. Sözcüklerle Yapılan Pekiştirme,

3. Eklerle Yapılan Pekiştirme,

4. Pekiştirme Edatları.

olmak üzere dört başlık altında ele almıştır.

İpek (2009), çalışmasının giriş bölümünde edat terimi, edatların sınıflandırılması, edatın tanımları, edatların özellikleri, edatların yapıları, pekiştirme ve pekiştirme türleri konusuyla ilgili genel bilgiler vermiş̧tir. Birinci bölümde ise "Türkçede Pekiştirme Edatları" başlığı altında Türk lehçelerinde kullanılan pekiştirme edatlarını incelemiştir. Bu bölümde Tarihî Türk lehçelerinden itibaren, çağdaş Türk lehçeleri de dâhil olmak üzere kullanılan pekiştirme edatlarına yer vermiştir. Pekiştirme edatlarının, kökeni, yapısı, kullanıldığı yerler ve fonksiyonları anlatılarak, lehçelerdeki kullanımlarını vermiştir. Çalışmanın ikinci bölümünde ise "Az Kullanılan Pekiştirme Edatları" 
başlı̆̆ altında sadece bir iki lehçede kullanılan fazla yaygın olmayan pekiştirme edatlarına yer vermiştir.

Karahan da Türkçede Bazı Ek ve Edatlarda “-n” Morfemi İle Ortaya Çıkan Varyantlaşma adlı makalesinde pekiştirme meselesine şöyle değinmiştir:

Türkçenin seçeneklerinden biri, kelime ve ekleri $-n,-l,-z,-t,-k,-m,-A,-I$ gibi çeşitli morfemler yardımıyla genişletmektir. Bir kısmı muhtemelen enklitik kökenli olan bu morfemler, Türkçenin her dönem ve lehçesinde görülür. Pekiştirilmiş kelime ve eklerle bunların önceki şekilleri arasında genellikle anlam ve işlev farkı görülmez. Çoğu zaman her iki şekil de aynı dönem ve lehçede kullanılmıştır (Karahan, 2012: 219).

Bahşi ise (2017) Ŏguz Grubu Türk Lehçelerinde Pekiştirme Unsurları ve Kurallarl adlı doktora çalışmasında pekiştirme unsurlarının Oğuz Grubu Türk lehçelerindeki kullanımları, ses ve şekil değişimleri, kökenleri, kullanıldığ yerleri, örneklerle tespit etmiştir. Bu amaçla Oğuz grubu lehçeleri içinde yazı dili olarak kabul edilen Azerbaycan Türkçesi, Türkmen Türkçesi ve Gagavuz Türkçesinden metinleri tarayarak Türkiye Türkçesinden de dil bilgisi kitapları incelemiştir.

Kamacı da (2015) Türkçede Pekiştirme (Anlamsal, Sözdizimsel, Yazımsal) adlı çalışmasında önce dilbilgisi, dilbilim ve pekiştirme kavramlarından söz ettikten sonra bağlamda meydana gelen pekiştirmeli anlatımları tespit etmiştir. Söz konusu pekiştirmeleri anlamsal, sözdizimsel ve yazımsal olmak üzere üç ana başlıkta ele almıştır.

Gül ise (2015) Kutadgu Bilig'de Enklitik Edatlart adlı makalesinde ok, ol, la, ma/me ve mat/met, erinç, erki ve yime kelimelerini enklitik edatları olarak değerlendirmiştir.

Okul (2016) Özbek Türkçesinde Pekiştirme ve Derecelendirme adlı yüksek lisans tezinde pekiştirme ve derecelendirme kavramlarına değindikten sonra İnceleme bölümünde konuyu detaylarıyla ele almış, taranan Özbek Türkçesi metinlerinden elde edilen örnekleri,

1. Eklerle Yapılan Pekiştirme ve Derecelendirmeler,

2. Son Çekim Edatlarıyla Yapılan Pekiştirme ve Derecelendirmeler,

3. Kelimelerle Yapılan Pekiştirme ve Derecelendirmeler,

4. Kelime Gruplarıyla Yapılan Pekiştirme ve Derecelendirmeler

başlıkları altında işlemiş̧ir.

Karagöz, (2018) TDK tarafından yayınlanan Tarihi Türk Lehçelerinde Slfat ve Zarflarda Pekiştirme ve Derecelendirme çalışmasında ilk önce pekiştirme ve derecelendirme kavramı üzerinde durduktan sonra

1. Türetimlik Biçim Birimleriyle,

2. Sözlük Birimleriyle,

3. Dizimsel Birimlerle,

4. Dizimsel Yapıyla İşaretlenen Pekiştirme ve Derecelendirmeler

olmak üzere pekiştirme ve derecelendirme konusunu dört başl1k üzerinde ele almıştır.

Yukarıda bahsedilen çalışmalarda pekiştirme meselesi, genellikle Türk lehçelerinin standart dildeki biçimiyle ilgilidir.

Doğrudan ağız çalışmaları üzerinde pekiştirme konusunu ele alan çalışmalar azdır. $\mathrm{Bu}$ çalışmalardan birincisi Demir (2014) tarafından kaleme alınan Güneybatı Anadolu Ağızlarındaki Pekiştirme Ekleri Üzerine adlı yazıdır. Bu makalede yazarın çalışma alanı, İzmir, Muğla, Denizli, Manisa, Uşak, Kütahya, Afyon'u kapsayan Güneybatı Anadolu ağızları ve bu ağızlara yakın olan Balıkesir ağzıdır. Çalışmada söz konusu bölgede tespit edilen pekiştirme ekleri üzerinde durulmuş, ayrıca bu tür yapıların türeme mi ek kalıntısı mı olduğu hususu tartışılmıştır.

Doğrudan ağızlara bakan bir diğer çalışma ise Manav'ın Kıbrıs Türk Ağızlarında Pekiştirme Ekleri, Pekiştirme Sıfatları ve Kuvvetlendirme Edatları isimli çalışmasıdır. Çalışmanın ilk bölümünde araştırmacı Kıbrıs Türk ağzında tespit edilen pekiştirme ekleri üzerinde durarak bunların türeme mi ek kalıntısı mı olduğunu tartışmıştır. İkinci bölümde ise Kıbrıs Türk ağzında pekiştirme sıfatı yapma yolları incelenerek standart dille örtüşme ve standart dilden ayrılma noktaları ele 
alınmıştır. Üçüncü bölümde de Kıbrıs Türk ağzındaki pekiştirme sözcüklerinden bazılarının Eski Türkçedeki izleri sürülmeye çalışılmıştır. academia.edu.tr'de tespit edilen bu çalışmanın künyesi tespit edilememiştir.

\section{DÖRTYOL AĞZINDAN DERLENEN METINDE TESPIT EDILEN PEKISSTIRME UNSURLARI}

\subsection{Pekiştirme Amactyla Kullanılan Sesler}

Dörtyol ağzından derlenen metinde tespit edilen pekiştirme olarak kullanılan sesler zarffiillerden, - $m a$ biçim biriminden ve ile edatından sonra gelmektedir.

\subsection{1. $-n$}

Ercilasun (2008)'de pekiştirme enklitikleri kelime türü ayırt etmeden; her türdeki kelimeden sonra gelebileceğini ifade eder. Bu doğrultuda Dörtyol ağzından derlenen metinde de pekiştirme olarak kullanılan - $n$ sesi hem fiillere hem de isimlere gelmektedir. -A zarf-fiiline gelen pekiştirme sesi şöyledir:

$$
\text { dǐè "diye" (1-2) diye- } \underline{n}
$$

Araştırıcıların çoğu, ek ve edatlarda varyantlaşmaya sebep olan $-n$ morfemini, vasıta eki veya zarf-fiil ekine bağlamıştır. Türeme bir ses veya bir pekiştirici olduğunu düşünenler de vardır. - $n$ morfeminin eski çokluk eki - $A n$ ile ilişkilendirildiği Üstüner 2003'te, - $n$ 'nin kökeni hakkındaki tartışmalara geniş̧e yer verilmiştir (2003: 87-96). Kökeni ne olursa olsun, geçirdiği merhalelerin bu noktasında, eklendiği kelime veya ekte genellikle belirgin bir işlev farkı ortaya çıkarmayışı, $n$ 'nin bir pekiştirici morfem olduğunu veya artık pekiş̧irici bir morfem hâline geldiğini göstermektedir (Karahan, 2012: 233).

tiyin / diyin edatı diye, diyerek anlamlarında Köktürk, Uygur, Karahanlı ve Kıpçak Türkçelerinde kullanılmıştır. tiyü / diyü ise yine aynı anlamlarda Harezm Türkçesi ile Batı Türkçesinde görülür (Hacıeminoğlu 1984: 198-199). Türkiye Türkçesi ağızlarında diyi yanında diyin/deyin/teyin şekilleri de bolca kullanılmaktadır (Yıldırım 2006: 199; Gemalmaz 1978: 308). Korkmaz'a göre tiyin / diyin kelimesinin sonundaki - $n$, bir zarf-fiil ekidir (1995: 155). Hacieminoğlu tegin, deyin / digin, tiyin gibi bazı şekillerin sonundaki - $n$ morfemini vasıta hâli eki sayar (1984: 31). diyi ve diyin kelimelerinin aynı işlevde kullanıldığı aşağıdaki örnekler, Adana'nın Ceyhan ilçesi ağzından alınmıştır: Aşāsın diyi daı diyi garşı vardı (Yıldırım 2006-II: 223). Ulan ahiretden adam gelir mi diyin dutar bunu bi düer (Yıldırım 2006-II: 228).(Karahan, 2012: 231)

Yukarıdaki açıklamalara bakarak Türkçede diye zarf-fiiline $-n$ sesinin pekiştirme amacıyla

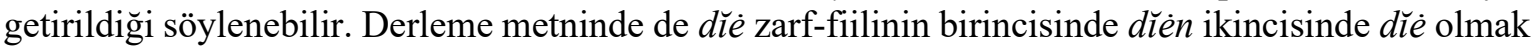
üzere iki defa kullanıldığı fakat bu iki kullanım arasında anlam farklılığı oluşmadığı görülmektedir. Buradan hareketle dièn kelimesindeki - $n$ sesinin pekiştirme amaçlı kullanıldığı söylenebilir.

il- fiilinden -e zarf-fiil ekiyle teşekkül eden ile edatı, Çağatay ve özellikle Batı Türkçesi sahasında yaygın olarak kullanılmıştır; ekleşmiş $-l A$ şekli de işlektir. Bu edatın $-n$ eki ile genişlemiş aynı işlevdeki ilen (-len) şekli, Çağatay ve Batı Türkçelerinde görülmektedir (Hacıeminoğlu 1984: 45-48).

Hacıeminoğlu'nun açıklamalarına benzer bir kullanım derleme metninde de tespit edilmiştir. ile- $n$ yapısının metnimizdeki kullanımı aşağıdaki örneklerdeki gibidir.

şiènen "şeyle" (1-1) şey ile $+\underline{n}$

habilinen gabil "Habil ile Gabil" (1-52) Habil ile $+\underline{n}$

ökeyinen "öfkeyle" (1-36) öfke ile $+\underline{n}$

Derlenen metinden aşağıdaki örnekte de $-e$ ve $-n$ sesleri pekiştirme amacıyla üst üste gelmiştir.

bunnar cenneddǐekinen "bunlar cennetteyken" (1-26) cennette $+\mathrm{y}+\mathrm{ken}+\underline{\mathrm{e}}+\underline{\mathrm{n}}$

Ek-fiile gelen -ken zarf-fiil ekinin üzerine $+A$ yönelme durumu ekinin getirilmesiyle oluşmuş bir ek grubudur. -KAnA ekinin geniş zaman sıfat-fiili üzerinde kullanılması yaygındır (Gülsevin 2000). Tespit ettiğimiz örneklerin büyük bölümü de bunu göstermektedir. Yazı dilimizde ekin 
kullanımına rastlanmamıştır. Fakat Anadolu ağızları yanında Genel Ağda yapılan bir taramada kimi ciddi konularda yazılan yorum ve yazılarda dahi ekin bu biçimiyle kullanıldığı görülmektedir. Kimi ağızlarda kalın sıradan kelimelere kalın ünlülü biçimiyle gelerek ünlü uyumuna uymaktadır (Argunşah, 2011: 63).

Anadolu ağızlarında $+A$ ile genişlemiş örnekler yanında nadiren $+A n$ ekiyle genişlemiş örnekler de vardır. Buradaki $-A$ yönelme durumu ekinden sonra gelen $+n$ 'nin araç durumu eki olduğunu düşünüyorum (krş. Yüce 1999: 75). -ArAkTAnA birleşiğinde olduğu gibi iki durum eki üst üste gelerek ek yığılması olayına sebebiyet vermiștir: gidēkenen (Uşak: 82). Oraya boyük bir gartal gelir, o suyun başına gonar sulanır; sulanırkanan atlarsın (Yüce 1999: 75) Birinde avdan dönerkenen (Yüce 1999: 75). (Argunşah, 2011: 63).

Argunşah'ın durum eklerinin zarf-fiilden sonra üst üste gelmesi olarak ifade ettiği dil yapısı, derleme metninde geçen cenneddĭekinen kelimesinin -ken $+\mathrm{e}+\mathrm{n}$ kısmında hem -e sesi hem de $-n$ sesi pekiştirme amacıyla kullanılmıştır.

\subsection{2. $-a$}

ondan sōramie "ondan sonra" (1-2), ondan sonra $+m a+y+\underline{a}$

Derleme metnindeki yukarıdaki örnekte ise -ma biçim birimi ve - $a$ sesi pekiştirme amacıyla üst üste gelmiştir.

galana çog üzüldü "artık, bundan sonra çok üzüldü” (1-25) $\dot{g} a+l a+\underline{n}+\underline{a}$

Artık anlamındaki kalan kelimesi, kalı, kanı, kayu, kaçan kelimeleri gibi bir ka köküne dayanmakta olup muhtemelen yapısında birle, tañla, tünle kelimelerindeki $-l A$ eki ile - $n$ pekiştirme morfemi bulunmaktadır. kalan kelimesi, Türkiye Türkçesi ağızlarında kalan ve galan şekillerinde yaygın olarak kullanılır (Derleme Sözlüğü, C.VI, VIII). (Karahan, 2012: 229).

Karahan'ın açıklamasında da değindiği gibi yukarıda derleme metninde tespit edilen galana kelimesindeki $-n$ ve $-a$ sesleri pekiştirme amacıyla kullanılmıştır. Burada da üst üste iki unsur gelmiştir.

uy̌rerkana "uyurken" (1-48) uyurken- $\underline{e}$

Yukarıdaki örnekte de i-ken zarf-fiili üzerine Anadolu ağızlarında da yaygın olarak kullanılan -e sesi getirilerek pekiştirme sağlanmıştır.

\subsection{Pekiştirme Amacıyla Kullanılan Biçim Birim Unsurları}

Türkçe Sözlük’te biçim birimi, "Kelimelere dil bilgisi bakımından biçim veren, çoğu ek durumunda olan öge, morfem.” şeklinde tanımlanmıștır. Fransızca CNRTL'de biçim birimi terimi morphème, "Bir kelime veya cümlenin paradigmatik sınıfının işlevini ve üyeliğini gösteren bir kelime veya cümlenin parçası." olarak tanımlanmıştır. Bu çalışmada biçim birimi terimi Türkçe Sözlük’teki karşılığıyla kullanılacaktır.

Biçim birim unsurları da Türkçede pekiştirme görevinde yaygın olarak kullanılmıştır Derleme metninden tespit edilen örnekler aşağıdaki gibidir.

\subsection{1. - -kine}

uyanmışkine "uyanmış ki" (1-50) uyanmış + kine

diyörkine "diyor ki" (1-54) diyo+kine

dèdikine "dedi ki" (1-29) dedi+kine

-qıña eki Türkiye Türkçesi ağızlarında çekimli fiilin üzerine gelerek pekiştirme işleviyle de kullanılmaktadır. Zeynep Korkmaz, Türkiye Türkçesi ağızlarında çekimli fiiller yanında kullanılan -qına/-kine pekiştirme ekinin bir Avşar ağzı özelliği olduğunu ve bu ağız özelliğinin Gaziantep, Malatya, Tunceli ve Elazığ ağızlarında etkili olduğunu belirterek şu örnekleri verir: dimişkine "demiş ki”, dmkine "diyor ki”, yatsakine "yatsa ki”, alsakine "alsa ki” (Alkaya, 2008: 61).

Alkaya'nın çalışmasında Köktürkçeden günümüze kadar hemen hemen Türkçenin bütün dönem ve sahalarında sıfatlara, zarflara ve fiillere geldiği tespit edilen bu ek, derleme metninde de 12 defa kullanılmıştır.

\subsection{2. $-c ̧ a$}


Pekiştirme enklitikleri ek sırası gözetmez; eklerden önce de sonra da gelebilir. Pekiştirme enklitikleri üst üste gelebilir. Pekiştirme enklitikleri + çA, +tI eşitlik ekleriyle ve $1, \mathrm{n}, \mathrm{y}, \mathrm{m}$ pekiştiricileriyle s1kça bir araya gelebilir (Ercilasun, 2008: 43).

o zamanançame "o zamana kadar"(1-26) o zaman $+\mathbf{a}+\underline{n}+\underline{+c} \mathbf{a}+\underline{m a}+\mathrm{y}+\underline{a}$

Ercilasun'un bahsettiği gibi pekiştirme unsuru - $m a$ ve $-c ̧ a$ 'nın üst üste gelerek kullanılması derlenen metninde birden fazla örnekte tespit edilmiştir. Yukarıdaki örnekte de anlamı iyice kuvvetlendirmek için - $n,-c ̧ a,-m a,-a$ pekiştirme unsurları üst üste gelmiştir.

-(y)ACA eki, isimlere - A kadar anlamı veren bir ektir. Korkmaz 1995'te ekin eski şekli olan -GAçA'nın Köktürkçede, Uygur ve Çağatay Türkçesinde sınırlandırma işlevi ile kullanıldığı belirtilmiştir. Ek, bugün Tarançı, Özbek, Tatar Türkçesinde ve bazı Sibirya lehçelerinde ve Türkiye Türkçesi ağızlarında kullanılmaktadır (1995: 28-29). - $C A$ 'nın $-A$ yönelme hâli ekinden sonra gelmesi, bu ekin ekvatif eki - $C A$ 'dan farklı edat kökenli başka bir ek olabileceğini düşündürüyor. $-A C A$ eki, bazı yörelerde $-n$ ve $-\mathrm{k}$ sesleriyle genişletilmektedir. Korkmaz'a göre bu $-n$, vasıta hâli ekidir (1995: 29). $-n$ ile genişlemiş $-A C A n$ ile $-A C A$ arasında işlev farkı yoktur:

Sabahaça gedellerdi (Yıldırım 2006-II: 431).

Telli Mehriban hindiyeçen bize deyirdi ki pırtı bahalıdı (Caferoğlu 1942: 33). (Karahan, 2012: 229).

Karahan'ın yukarıdaki çalışmasında da bahsettiği gibi -ça eşitlik eki derlenen metinde pekiştirme görevinde kullanılmıştır. Ayrıca derleme metnimizde -ça ekinden önce ve sonra da pekiştirme unsurları kullanıldı ğı görülmektedir. Bunun yanı sıra dört tane pekiştirme unsurunun bir sözcükte kullanılması da dikkat çekici bir husustur.

\subsection{3. $-m a$}

ondan sōramie "ondan sonra" $(1-2,32)$, ondan sonra $+\underline{m a}+y+\underline{a}$

Derleme metninde kullanılan -ma ekinin kaynağı hakkında farklı görüşler vardır.

Pekiştirme işlevine sahip $+\mathrm{mA} / \mathrm{mA}$, Karahanlı metinlerinde sözlük birimi (adın ma, idi me, ne me, neçe me, üküş me, takı ma yana ma); Uygur, Harezm ve Eski Anadolu Türkçesi metinlerinde türetim biçim birimi görünümündedir (Uyg. ançama, Harz. neme, neçeme, EAT. nemçeme) (Karagöz, 2018: 89).

Kutadgu Bilig'de aşağıdaki örneklerde $+c ̧ A$ ekinden sonra gelerek pekiştirme görevinde kullanılmaktadır. Bu durumda $+m A / m A$ pekiştirme unsuru, kendisinden önce gelen neçe sözcük birimini pekiştirmektedir. Ayrıca - $m a$ 'nın kendisinden önceki kelimeye hem bitişik hem de ayrı yazılması hem sözcük hem de biçim birim olarak kullanıldığını gösterir. Daha sonraki dönemlerde sadece biçim birim olarak kullanılmıştır.

neçe me tok erse yègü beg aşı

bu begler aşı ol ağırlık başı

"İnsan ne kadar tok olsa bile beyin yemeğini yemelidir, bu beylerin yemeği ikbalin başlangıcıdır.” (4133). (Arat, 2007: 416).

neçeme mèni edgü tutsa özün

yoñaģ̧ı yoñasa tügülgey yüzün

"Sen bana ne kadar iyi gözle baksan bile gammazların fitneleri seni benden soğutabilir." (5860). (Arat, 2007: 581).

\subsection{Pekiştirme Amacıyla Kullanılan Söz Dizimi Unsurları}

Türkçenin her döneminde rastlanan aynı, yakın ya da eş anlamlı sözcük unsurlarının pekiştirme amacıyla bir araya gelmesidir. Derlenen metinde tespit edilen ikileme yapısıyla kurulan bazı örnekler şu şekildedir.

kibirlendi marurland1 "gururland1, kibirlendi" (1-12).

cenneddā kokulandı, burculandı geldî (1-7).

hē hē "evet, evet" (1-11). 


\title{
3. SONUÇ
}

Derleme metni üzerinde yapılan incelemede ses birimi, biçim birimi ve söz dizimi düzeyinde pekiştirme amacıyla kullanılan birbirinden farklı unsurlar tespit edilmiştir. Bunlar, $-a$ ve $-n$ sesleri, ça, -ma ve -kine biçim birimleri ile aynı ve yakın anlamlı sözcüklerin tekrarından oluşan söz dizimi unsurlarıdır. Literatür taramasında pekiştirme amacıyla kullanılan ses birimi, biçim birimi ve söz dizimi düzeyinde pekiştirme unsurlarının kullanıldığı birçok çalışmaya rastlanmıştır. Dörtyol ağzı üzerine yapılan her iki akademik çalışmada da, bu çalışmalar genel ağız incelemeleri olduğu için, doğrudan pekiştirme amacıyla kullanılan unsurlara değinilmemiştir. Çalışmamızda pekiştirme amaçlı ses birimi ve biçim birimi unsurlarının bazen tek başına kullanıldığı; bazen de aynı kelimede iki, üç hatta dört unsurun üst üste kullanıldığ görülmektedir. Bu katmerli kullanım duygu ve düşüncelerin önemini vurgulamak için dilin imkânlarından üst düzeyde yararlanıldığını göstermektedir. Bu durum Türkçenin anlatım imkânlarının ne denli zengin olduğunu göstermesi açısından oldukça önemlidir. Ses birimi ve biçim birimi unsurlarının pekiştirme amacıyla üst üste kullanılması standart Türkçede fazla rastlanmayan bir özelliktir. Şair ve yazarlarımız zaman zaman Türkiye Türkçesi ağızlarından özellikle sözcük düzeyinde faydalanmışlardır. İhtiyaca göre ve belirlenen esaslar çerçevesinde Türkiye Türkçesi ağızlarından standart Türkçeye bazı unsurlar kazandırılabilir.

Yukarıda bahsedilenlerin yanı sıra Türkiye Türkçesi ağızları üzerine yapılacak kapsamlı çalışmalar sonucunda, nitelik olarak birbirinden farklı pekiştirme amacıyla kullanılan pek çok unsurun tespit edileceği düşünülmektedir. Bu çalışma, Türkiye Türkçesi ağızlarında pekiştirme amacıyla kullanılan unsurlarla ilgili araştırmalara küçük de olsa bir katkı sağlamayı amaçlamıştır.

\author{
Çeviriyazı İşaretleri \\ ā: uzun a \\ ă: k1sa a \\ è: kapalı e \\ è: uzun e \\ ì: uzun 1 \\ î: uzun $\mathrm{i}$ \\ 1: k1sa i \\ ō: uzun o \\ ō: uzun ö \\ ū: uzun u \\ ŭ: k1sa u \\ ü: kısa ü \\ h.: girtlak h'si \\ g: arka damak ünsüzü g \\ k: arka damak ünsüzü $\mathrm{k}$ \\ ñ: geniz n'si
}

\section{KAYNAKÇA}

Alkaya, E. (2008). Eski Türkçe -qıña Ekinin Türk Lehçelerinde ve Türkiye Türkçesi Ağızlarında Kullanımı Üzerine. Turkish Studies, 3(4), 43-72.

Yusuf Has Hacip (1979). Kutadgu Bilig I, Haz. Reşit Rahmeti Arat, İstanbul: Türk Dil Kurumu Yayınları.

Argunşah, M. (2011). Türkçede Zarf-Fiil Eklerinin Durum Ekleriyle Kalıplaşması. Turkish Studies, 6(1), 5568. 
Aslan, S. (2002). Türkiye Türkçesinde Slfat ve Zarfların Pekiştirme ve Derecelendirme Yollar, Yayımlanmamış Yüksek Lisans Tezi, Gazi Üniversitesi Sosyal Bilimler Enstitüsü, Ankara.

Bahşı, B. (2017). Oğuz Grubu Türk Lehçelerinde Pekiştirme Unsurları ve Kurallar, Yayımlanmamış Yüksek Lisans Tezi, İnönü Üniversitesi Sosyal Bilimler Enstitüsü, Malatya.

Demir, İ. (2014). Güneybatı Anadolu Ağızlarındaki Pekiştirme Ekleri Üzerine. Uşak Üniversitesi Sosyal Bilimler Dergisi, 7(2), 106-124.

Ercilasun, A. B. (2008). La Enklitiği ve Türkçede Bir 'Pekistirme Enklitiği' Teorisi. Dil Araştırmaları Dergisi, $2,35-56$.

Ergene, O. (2013). Tarihi Türk Yazı Dillerinde Hece Yinelenmesi İle Kurulan Pekiştirilmiş Sözcükler, Ç. ̈U. Sosyal Bilimler Enstitüsü Dergisi, 22 (1), 61-84.

Hacıeminoğlu, N. (1984). Türk Dilinde Edatlar, Ankara: Milli Eğitim Bakanlığı Yayınları.

Hatiboğlu, V. (1972). Türkçenin Sözdizimi, Ankara: TDK Yayınları.

Hengirmen, M. (1999). Dilbilgisi ve Dilbilim Terimleri Sözlüğü, Ankara: Engin Yayınları.

İpek, B. (2009). Türkçede Pekiştirme Edatları, Yayımlanmamış Yüksek Lisans Tezi, Fırat Üniversitesi Sosyal Bilimler Enstitüsü, Elazı̆̆.

İmer, K., Kocaman A., Özsoy A. S. (2011), Dilbilim Sözlüğü, İstanbul: Boğaziçi Üniversitesi Yayınevi.

Kamacı, D. (2014). Türkçede Pekiştirme (Anlamsal, Sözdizimsel, Yazımsal), Yayımlanmamış Yüksek Lisans Tezi, Eskişehir Osmangazi Üniversitesi Sosyal Bilimler Enstitüsü, Eskişehir.

Karagöz, İ. (2018). Tarihi Türk Lehçelerinde Slfat ve Zarflarda Pekiştirme ve Derecelendirme, Ankara: Türk Dil Kurumu Yayınları.

Karahan, L. (2012). Türkçede Bazı Ek ve Edatlarda “-n” Morfemi İle Ortaya Çıkan Varyantlaşma. Bülent Gül (Ed.), Türk Moğol Araştırmaları Prof. Dr. Tuncer Gülensoy Armăganı (s. 219-236), Ankara: Türk Kültürünü Araştırma Enstitüsü Yayınları.

Korkmaz, Z. (1995). Türk Dili Üzerine Araştırmalar, Ankara: Türk Dil Kurumu Yayınları.

Korkmaz, Z. (2007), Gramer Terimleri Sözlüğü, Ankara: TDK Yayınları.

Manav, E. (Ty.). Kıbrıs Türk Ağızlarında Pekiştirme Ekleri, Pekiştirme Sıfatları ve Kuvvetlendirme Edatları. https://www.academia.edu.tr

Okul, R. (2016). Özbek Türkçesinde Pekiştirme ve Derecelendirme, Yayımlanmamış Yüksek Lisans Tezi, Gazi Üniversitesi Sosyal Bilimler Enstitüsü. Ankara.

Sezer, Ö. (2006). Türkiye Türkçesi Ağızlarında Zarflar ve Zarf Yapımı, Yayımlanmamış Yüksek Lisans Tezi, Afyon Kocatepe Üniversitesi Sosyal Bilimler Enstitüsü, Afyon.

Üstüner, A. (2003). Türkçede Pekiştirme, Elazı ğ: Fırat Üniversitesi Basımevi.

Yazıcı, S. (2006). Dörtyol Ăğı, Yayımlanmamış Yüksek Lisans Tezi, Yüzüncü Yıl Üniversitesi, Van.

\section{Elektronik Kaynaklar}

https://www.cnrtl.fr/definition/morpheme adresinden 28 Ağustos 2020 tarihinde erişilmiştir.

https://sozluk.gov.tr adresinden 02 Aralık 2020 tarihinde erişilmiştir. 


\section{EXTENDED SUMMARY}

\section{Purpose}

In this study, reinforcement elements in a narrative text compiled from Hatay Dörtyol dialect were tried to be identified and examined. Although there have been many studies on the elements used as reinforcement in standard Turkish, it can be said that studies directly examining the reinforcement elements used in Anatolian dialects are not sufficient. Dörtyol has become a Turkish homeland with Turkish migrations in different periods since the 7th century. Turkish elements living in Dörtyol have managed to preserve their language and cultural characteristics despite living with different cultures for centuries. In the dialect of Dörtyol, there are reinforcements used in standard language as well as reinforcements that cannot be shown in standard language. In this study, firstly, brief information about the academic studies about Dörtyol dialect will be given. Afterwards, reinforcement elements that differ from the standard language will be examined on the text.

\section{Methodology}

In this study, firstly, studies on reinforcement in Turkish are mentioned. Later, information was given about the settlement of Turks in the region and the academic studies on Dörtyol. In 2019, a folk narrative about the removal of Prophet Adam and Eve from heaven and their reunion on earth by a person named Mehmet Fil from Dörtyol dialect was compiled and written. Reinforcement elements were determined from the created text and they were classified with the traditional method and some evaluations were made on the findings.

\section{Findings}

Each person understands things and events to the extent that he develops his material and spiritual abilities while accessing knowledge. The expressions and descriptions he uses while describing objects and events are in the extent of his own sense, pleasure and knowledge. The adjectives and adverbs used to describe the fine properties of objects and the details of events are important. In addition to the standard spoken language, there are dialects that develop in parallel with the standard spoken language. Dialects that do not have a written tradition in the expression of feelings and thoughts have some features different from the standard language, although they are a sub-segment of the language. Over time, these two spoken languages affect each other. In the current period, the increase in the rate of literacy and the rapid spread of mass media cause the rapid loss of dialect features.

In the text compiled from Dörtyol dialect, reinforcement elements are examined under three headings: phonemes, morphemes and syntax.

The phonemic - $n$, which is determined in the review text and used as a reinforcement element, comes after the adverb-verbs and the preposition ile. With these features, the reinforcement element $-n$ phoneme carries some traces of historical dialects and overlaps with some Anatolian dialects. In addition, the phoneme -n can be added to both verbs and nouns. In some examples in the compilation text, it is seen that the phonemes overlap in order to increase the degree of reinforcement. In this context, in the word galana, the - $\mathrm{n}$ and -a phonemes belonging to the same category were used one after the other for reinforcement.

In some examples in the compilation text, the -a phoneme and -ma morpheme, which are used as reinforcement elements, are overlapped for reinforcement. Here, the degree of in some examples in the compilation text, the -a phoneme and -ma morpheme, which are reinforcement is increased by using reinforcement elements belonging to different categories together.

The -e phoneme, which is also widely used in Anatolian dialects, is reinforced in the examples in the compilation text by adding the i-ken adverb-verb.

Morpheme elements are also widely used in the Turkish reinforcement task.

The -kine morpheme, which has been used in many fields from the first written examples of Turkish until today, is frequently used in this compiled low-volume text.

The suffix -ça equality, which has been used since the first written works of Turkish, was also used in the compilation text to reinforce it. The word zamanançame is a remarkable example in terms of showing the overlapping of reinforcement elements. Because four reinforcement elements, 
-n, -ça, -ma, -a overlap. This accumulation of reinforcement is not unnecessary and comes from the need for the narrator to express his intention.

Overlapping of the -ça and -ma morpheme shapes of the reinforcement element in the compilation text has been determined in more than one example.

The morpheme -ma, which contains different opinions about its source, is sometimes used alone or in combination with other reinforcement elements in the compilation text.

Reinforcement elements formed in the form of duplication with close or synonymous words are encountered in every period of Turkish. Two examples of the reinforcement element established with the duplication structure determined in the compiled text were identified. These reinforcement elements are made with words with close meaning.

\section{Conclusion and Discussion}

Reinforcement elements in standard spoken language are more than written language. Because, reinforcement is provided with emphasis and intonation in spoken language. Many reinforcement elements used in the standard language are also used in Anatolian dialects. In the text analysis compiled from Dörtyol dialect, significant reinforcement elements in terms of quality and quantity were determined. One of these features is the overlap of two, three or even four reinforcement elements.

It is a known fact that standard language contributes to Anatolian dialects and Anatolian dialects contribute to standard language. If there are so many different reinforcement elements in a single compilation text, it is obvious that there will be many reinforcement elements in comprehensive studies on Anatolian dialects. Identifying reinforcing elements in Anatolian dialects and using them in standard language may contribute to the standard language. 


\section{Derleme Metni}

Kaynak Kişi: Mehmet Fil

Yaşı ve Mesleği: 76, Emekli İşçi

Derleme Yeri: Hatay / Dörtyol

hazreti ādem şėyden yapıldı, balçağdan. çamırdan. è şiènen, cebraili saldı üce rabbım tobrag vèrmedi. cehennemde yanar dïèn. ondan sōramǐe, şı̈è saldı, mikaili saldı, vermedi. azreile dèdi sen alıñ. ben dedi alîm amma dẻdi, canın satın, alıcım dẻdi, ayle efratı bize bẻdda ėder dẻdi. durdu, neyse sen alıcıñ dédi üce rabbım. iè ondan sonamǐe, bir pança izinsiz ġırmızı tobrăa vurdu, bir pençe şiè vurdu, siyaha. bir pençe ş̌̃e vurdu, beyaza. üçünü bir aldılar melegler, yūrdular, kokuladılar bu şie, ikǐe pöldüler. birin cennete addılar birin cehenneme. duyuşumuz. ondan sōnamǐe. orda, cenneddā kokulandı, burculandı geldî, cehennemdā da gavrıldı geldi, yandı. cehennemlig cennedlig orda ayrıldı geldi. uruflar yaratıldı işde şey. adem. adem babamız şı̈è oldu, şey yani.

cennetle cehennemden geldi topraklar geri

hē hē. cennedden de geldi cehennemden de. gèri gatıldı, yūruldu, ādem babamıziñ galafatı yapıldı. yapılınca ġalafatı; şėy dẻdi. şèytan da mücerripidi orda. è melegleriñ hocasîdi. kibirlendi marurlandı, şeytan. è sejde èt dèdiler kibirlendi şėytan. ben dèdi ateşperesdenim dẻdi, ādem dèdi tobrag̉dan. sejde èdmem dẻdi. dörd tarafını bir dolandı, iki sefer üç sefer şėytan, göbāne tükürdü, orta yerine. tükürdü, tükürünce; melegler de ġıvraddı o göbăe addı. ondan sona ādemi hāsil èddiler yani. ādeme can vèrdiler üs tarafına, ayücü balçağ. göbegden aşşāsı, üs yanna can vèrdiler. dedikine ādeme, bĭöglenme baġ, böbürlenme, tobraġdansıñ. balçaġdan dẻdiler ādeme. ādemi gèri bayılddılar, gèri her tarafı insana kesdi, āladı yalıñızım dỉe. ālı̌ence gèri bayılddılar, ş̌e havayı; böyüg bir ġız ş̌eyden oldu. amelǐet èddiler. amelǐet de ondan ġaldı, bōründen bir èye çıbī aldılar, sol tarafından melegler. sol tarafından ādemiñ, o şı̇e alınça çıī havayı hāsil èddiler, Allah'ıñ emrînen yaraddılar. ordan, şĭapınca, bu ādemi geri cana getirdiler, hava da başucunda oturǐodu. ādem elini sündü, hav̌e. dur dèdiler melegler bilānden yapışdılar. nikah yog haram saña şindi dèdiler. melegler nikahini ġıdı, havienen şı̈ cennete goydu ādemi. ondan sōnamǐe nikahini gıydık kèri cennete goydular. şèten atıldı ādemiñ yüzünden, şeyden, melegleriñ hocalīndan. atılınca şı̌oldu, naledleme toku geşdi, şèytana. ... ġalana çog üzüldü, ādeme dèdi ömür boyu kötülüg yaparım, ādemden törǐene dèdi. şaşırdırım kötülüg yaparım dẻdi. o zamanançame, bunnar cennedděekinen yılan da cennetiñ begcisîdi deve şeklinde, deve gimîdi boyu, yılanıñ. şèytan naled gelǐo, yılan dẻdi ki dẻdi nǐe âlioñ dẻdi, nǐe ālamǐem dẻdi. ādem beni gōôdurdu dèdi şindi cennedde dẻdi. ben bunnarı yoldan nasıl çıkarrım dèdi. o da dẻdikine, dilimiñ altına gir dẻdi küçül dẻdi, gonuş dẻdi. o ağaşdan buyda acından yèrsenîz, şı̈èaparsınız, ölmessiñiz. şèytanıñ diliniñ altına girdi, ondan sōramı̌e şièy, dedikine ādeme şo dèdi şeyden yẻmesseñiz ölürsüñüz. àdem dẻdikine Allah yasağladı dẻdi biz dẻdi ası gelemeg dedi yèmem dèdi. yèmedi âdem. avrada geldi avrad dẻdikine, avrada, o dẻdi buydaydın yėmesseñiz ölürsüñüz dèdi şeytan. o da dèdikine ādeme danışıyım da dẻdi. ādeme danışdı, ādem kesinligle yème hā dèdi. şeytan yavraldı, ölürsüñüz dedi. burada dẻdi galmassıñı, ölürsünüz amma buyda ağacını yèrseñiz ölmessiñiz dèdi. halbukı yasag. bu duddu hava ökeyinen bir pança ġabdı yėdi. yiènce ādeme dedikine ben sā gallım sen ölüñ dẻdi, yavraldı, dizleriniñ önüne çögdü, ille sen de yè. ādem dedikine yog āsı gelirig, yok. duddu ādemiñ ş̌ènden aldı yẻdi. şı̌e ādemi de şaşırddı avrad. avrad şaşırddı, şėytan şaşırdamadı, yẻdi. ādem de yẻdi. bunnar yèdî. bunnardan bir pislig hāsil oldu, ayŭuş̧larından. burunnarına tuddular burun ġlı biddi. yani kokulǐence burun ġlı biddi. ondan sōna goltuglarına çaldılar, eteg ġılı, şı̇ ġoltug ġ̀lı etāne çaldılar eteg ġılı, bunnar atıldı. cennedde pislig gabil olmaz. he hē gabil èdmez cenned. bunnar atıldılar. biri hicč̌e atıldı, biri ciddǐe. bir livayete göre yẻdi gün, bir livayete göre yėdi sene, bulamadılar birbirini. hava anamız, dutardı iki daşı birbirine çakardı balī bişirir yërdi. ādem babamız āç susuz havie arardı. gece gündüz arardı. hava gèce gündüz arardı, ādem babamız gèce yatar, gündüz arardı. şindi duddu ş̌̆abdı. bunnarı serenceg dā mı dǐollar ne dǐollar, orda birleşdiler gèri gayanıñ arkasında. ādem babamız uyumuş gece atirafin dolanmış hava. dolanınca dèmişki işallah dèmiş izini gördüm, yüzünü de görrüm demiş ādem babamız havanın. hava etirafın dolanmış ādem babamız uyı̌erkana, beni demiş şindi bulursa dẻmiş, hava anamız, mudareddiñ geldiñ dèr dèmiş hava anamız, ādem dèmiş. mudara ėdmǐem dèmiş gayanıñ arkasına 
geçmiş. ādem babamız uyanmışkine izi orda, işallah izini buldum dèmiş, gendin de bullum dèmiş. aramışkine ġayanıñ arkasında. orda birleşıollar, orda, ondan sōra çocug doğuyör, bir çid çocug doğuyör her sene. bu seneki çocū öbür seňie töremeg için o seneki çocū bu senǐe. habilinen gaabil de biribirin öldürüyör. fesadlı̀ ondan ileri geliyör, habilinen ġabilden. onnar şey için, benim bacım güzel seniki çirkin. bir de habil gabili, diyörkine sene diyör g goyun güddürïör seni çog seviör yaylada, beni sēmiör harman çıkaddirör, dïor. onuñ içi, ġısgacçlīndan. dî̀ o tarafdan, anaşidler, gısgaaçlıg orda, ondan sōra da dā çekilig gedîör. ondan soramiye da işde ş̌apiör, yasaġlanı̈ör, haram oliör, yẻdi göbeg berinden hala ġızından haric, emmi ġızından dayı ġızından haric, düşmez insana birbirine. añ yakın bunnar yani. evet, Allah'ıñ emri. bōle işde yı̌enim, ādem babamızıñ hayatı böle.

Peki dünya nasıl yaratılmış onu da biliyor musunuz?

benim bilgim yog̀ ondan. bunu duyūm. 